\title{
Interrelation of Social and Psychological Adaptation and Tendency to Deviant Behavior of Students
}

\author{
Yuliya Tagirovna Ibatullova ${ }^{1}$, Igor Olegovich Vasyukhno ${ }^{2}$, Alla Vladimirovna Frolova ${ }^{3}$, Flera Gabdulbarovna \\ Mukhametzyanova $^{4}$, Elena Vasilyevna Zelenkova ${ }^{5} \&$ Victoria Vladimirovna Sadovaya $^{3}$ \\ ${ }^{1}$ Volga Region State Academy of Physical Culture, Sport and Tourism, Kazan, Universiade Village, 33, \\ Russian Federation \\ ${ }^{2}$ The Main Department of the Ministry of Internal Affairs of Russia in Moscow region, Moscow, Russian \\ Federation \\ ${ }^{3}$ Kazan (Volga region) Federal University, Kazan, Kremlyovskaya Street, 18, Russian Federation \\ ${ }^{4}$ The University of Management of Tatar Institute of Business Cooperation, Kazan, Mushtari Street, 13, \\ Russian Federation \\ ${ }^{5}$ Kazan State Conservatoire (Academy) named after N. Zhiganov, Kazan, B. Krasnaya Street, 38, Russian \\ Federation \\ Correspondence: Yuliya Tagirovna Ibatullova, Department of service and tourism of Volga Region State \\ Academy of Physical Culture, Sport and Tourism Kazan, 420138, Russian Federation. E-mail: \\ ibatullova@mail.ru
}

Received: September 22, 2014 Accepted: December 17, 2014 Online Published: December 20, 2014

doi:10.5539/ass.v11n2p290

URL: http://dx.doi.org/10.5539/ass.v11n2p290

\begin{abstract}
The tendency to deviant behavior of students is a negatively affecting factor to the success of their socialization. Its actualization can lead to serious consequences, and become the reason of personality degradation even its death. Some reasons of the tendency to deviant behavior are violations of social and psychological adaptation. The interrelation of positive and negative factors of social and psychological adaptation with the tendency to various forms of deviant behavior is studied in this research. It is established that students' positive elements of social and psychological adaptation, such as high adaptation, self-acceptance and acceptance of others, internal control negatively effect on possibilities of the tendency development to various forms of deviant behavior. As for negative elements of social and psychological adaptation, such as disadaptation, self-unacceptance and unacceptance of others, emotional discomfort, external control and escapism can lead to strengthening of the tendency to deviant behavior. Positive and negative elements of social and psychological adaptation on the tendency to deviant behavior of students-boys are much lower than that of students-girls.
\end{abstract}

Keywords: social and psychological adaptation, disadaptation, tendency to deviant behavior, students

\section{Introduction}

In modern society there is an acute problem of the effectiveness of socio-psychological adaptation of personality and its adequate behavior in socium. The success of adaptation is defined by those changes which happen in the personality: self-assessment change, level of claims, "self-concept" structure, self-affirmation instalations (Masalimova et al., 2014). In general adaptation is estimated as the ability to adapt to the action of environmental factors, to react adequately in non-standard situations (Gadelshina, 2011; Ramakrishnan \& Dhanya, 2014).

Deviant behavior expresses the social and psychological status of the personality on the "socialization-disadaptation-isolation" axis. This is a stable behavior of a person, deviating from the most important social norms, causing real damage to society or the individual, but also accompanied by a social disadaptation (Zmanovskaya \& Rybnikov, 2011).

The training period in higher education institutions is an important stage of socialization and socially-psychological adaptation of the individual. The students is a special social group, possessing 
characteristics such as performance of certain functions in the society, the objective existence, the unique deterministic behavior of group members, a certain integrity and independence in relation to other social groups, specific socially-psychological traits and values (Cheverikina, 2012).

The features of social and psychological adaptation of students prone to deviant behavior associated with destructive areas of cooperation in the system "personality-socio-cultural environment" are expressed in the simplification of the internal structure and the destruction of the structural integrity of the individual (Gilemkhanova, 2013).

Thus, the study of interrelation of social and psychological adaptation and tendency to various forms of deviant behavior of students seems relevant, will enhance understanding of the features of these two phenomena, and identify areas of psycho-pedagogical activities to minimize the negative effects of students behavior.

\section{Literature Review}

In modern Russian psychological researches the main attention is paid to study of various aspects of deviant behavior of teenagers. It is noted that the nature of teenager deviant behavior depends on how he is taught to respond to arising difficulties in general by creative or destructive actions; how society, macro-and the microsocium, stimulates social-innovative, creative actions of the personality or on the contrary, doesn't stimulate them (Zhdanova, 2012). According to the data obtained by some researchers many older adolescents, particularly girls, are more prone to the manifistation of various forms of deviant behavior (Bessmertnaya, 2014). They studied the interrelation of character accentuations with deviant behavior of teenagers (Kaletinskaya \& Onufriyeva, 2014) and the features of adolescents' identity with deviant behavior (Yasnsaya, 2013). Practical recommendations on formation of a disciplinary responsibility of teenagers with deviant behavior were offered (Radetskaya, 2013), and the ways to overcome difficulties arising in the process of communication development and socialization of the child with deviant behavior in difficult life situation and formation of their sympathy (Novik, 2014).

There were presented the research results of the social and psychological characteristics of students who are prone to this type of deviant behaviour as addictive (Cheverikina et al., 2014).

Foreign scientists studied the effect of parental divorce on the tendency of adolescents to delinquent behavior (Heshmatollahet al., 2014), the relation between anxiety and depression and risk of development of socially deviant behavior of students (Shahsavari, 2012). The relationship study between the positive and negative aspects of social and psychological adaptation and the tendency to various forms of deviant behavior was not enough conducted.

\section{Research Methodology}

Object of research: students of higher education institutions.

Subject of research: interrelation of social and psychological adaptation, tendency to various forms of deviant behavior.

Research problems: to carry out the theoretical analysis of scientific literature on a problem of socially-psychological adaptation and the tendency to deviant behavior; to conduct an empirical research using the appropriate tools for students to identify the characteristics of interrelation of social and psychological adaptation and the tendency to various forms of deviant behavior.

In total 137 students of various establishments of higher education took part in research from several cities of the Russian Federation: 53 young men and 84 girls aged from 19 till 22 years.

The Research was conducted using the following standard techniques:

1) The diagnostic technique of the tendency to deviant behavior, which is a standard test-questionnaire to measure readiness (tendency) of personality to the implementation of various forms of deviant behavior. The questionnaire is a set of specialized psycho-diagnostic scales directed on measurement of readiness (tendency) for realization of separate forms of deviant behavior. Scales of a questionnaire are directed on measurement of the psychological content of a complex forms of deviant behavior connected with each other, that is the social and personal installations behind these behavioral manifestations (Kleyberg, 2004).

2) The diagnostic technique of social and psychological adaptation is developed by famous American psychologists R. Rogers and K. Daymond. It is adapted by Osnitsky A. K. for Russia. The technique as the measuring tool revealed high differentiating ability in diagnostics not only a state of adaptation and disadaptation, but also features of ideas of themselves, their reorganization during the age critical periods of 
development and in the critical situations inducing individuals to revaluation of themselves and their opportunities (Fetiskin et al., 2002).

\section{Data Analysis and Results}

The correlation analysis results of the data obtained by techniques used in research on selection as a whole are presented in Figure 1.
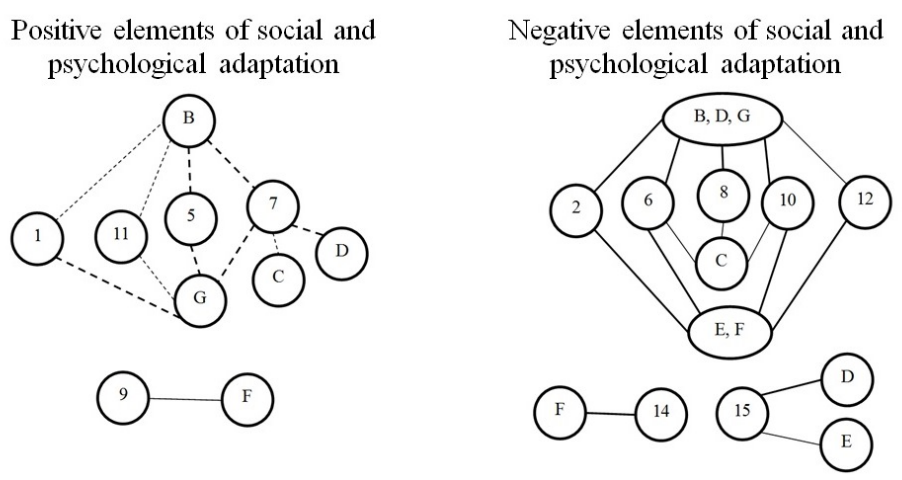

Figure 1. Interrelation of elements of social and psychological adaptation of deviant behaviour at students in general

Notes: I) 1-adaptation, 2-disadaptation, 3-negative falsity, 4-positive falsity, 5-acceptance of ourselves, 6-unacceptance of ourselves, 7-acception of others, 8-unacceptance of others, 9-emotional comfort 10-emotional discomfort, 11-internal control, 12-external control, 13-domination, 14-leading 15-escapism; b) A-setting in the social desirability of responses, B-tendency to overcome the rules and regulations, C-tendency to addictive behavior, D-tendency to self-harm and self-destructive behavior, E-tendency to aggression and violence, F-strong-willed control of emotional reactions, G-tendency to delinquent behavior; C) continuous lines-direct connections, dashed lines-feedback, bold lines-correlation is significant at the level of $\mathrm{p} \leq 0.01$, thin lines-correlation is significant at the level of $\mathrm{p} \leq 0.05$.

As you can see, almost all of the positive elements of the social and psychological adaptation of the students have a negative relation with the tendency for various forms of deviant behavior. Only emotional comfort is directly related to strong-willed control of emotional reactions.

Negative elements of social and psychological adaptation have direct connections with various forms of tendency to deviant behavior. Thus, the tendency to overcome norms and rules, to self-damaging and self-destroying behavior and delinquent behavior is affected by disadaptation, self-unacceptance, unacceptance of others, emotional discomfort and external control. The tendency to addictive behavior is connected with self-unacceptance and unacceptance of others, as well as emotional discomfort. The tendency to aggression and violence, as well as weak-willed control over emotional manifestations is connected with disadaptation, self-unacceptance, emotional discomfort and external control. To strengthen the tendency to self-damaging and self-destroying behavior and aggression and violence directed at others, also affects the escapism, and the weak-willed control over the emotions is connected with knowledge.

Positive elements of social and psychological adaptation

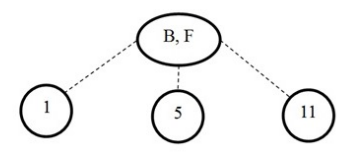

Negative elements of social and psychological adaptation

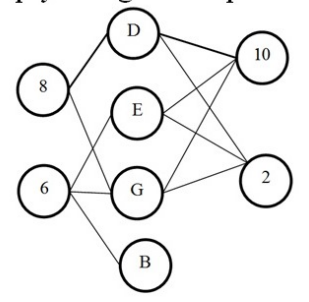

Figure 2. Interrelation of elements of social and psychological adaptation to deviant behaviour of students-boys 
The correlation analysis results of the data obtained by the methods used in the research of students-boys are presented in Figure 2.

Notes: a) 1-adaptation, 2-disadaptation, 3-negative falsity, 4-positive falsity, 5-self-acceptance, 6-self-unacceptance, 7-acceptance of others, 8-unacceptance of others, 9-emotional comfort, 10-emotional discomfort, 11-internal control, 12-external control, 13-domination, 14-leading, 15-an escapism; b) A-installation on social desirability of answers, B-tendency to overcoming of norms and rules, C-tendency to the addictive behavior, D-tendency to self-damaging and self-destroying behavior, E-tendency to aggression and violence, F-strong-willed control of emotional reactions, G-tendency to delinquent behavior; c) continuous lines-direct connections, dashed lines-feedback, bold lines-correlation is significant at the level of $\mathrm{p} \leq 0.01$, thin lines-correlation is significant at the level of $\mathrm{p} \leq 0.05$.

The tendency to overcome the rules and regulations is reduced and the tendency to strong-willed control of their emotions is increased at students-boys with a high level of social and psychological adaptation of self-acceptance and internal control. Other positive aspects of social and psychological adaptation do not have a significant affect on the tendency to various forms of deviant behavior.

The tendency to overcoming of norms and rules at students-boys amplifies at self-unacceptance that also leads to strengthening of the tendency to self-damaging and self-destroying behavior and to aggression and violence. Disadaptation and emotional discomfort affect as well as on strengthening of the tendency to self-damaging and self-destroying behavior and to aggression and violence, and also the tendency to delinquent behavior. The tendency to self-damaging and self-destroying, and also to delinquent behavior of students-boys is caused also by unacceptance of others.

The correlation analysis results of the data obtained by techniques used in research at students-girls are presented in Figure 3.
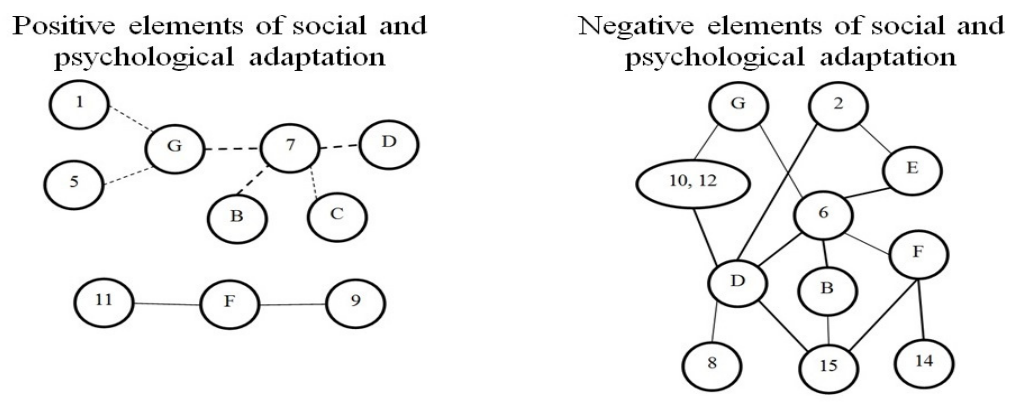

Figure 3. Interrelation of elements of social and psychological adaptation to deviant behavior of students girls

Notes: a) 1-adaptation, 2-disadaptation, 3-negative falsity, 4-positive falsity, 5-self-acceptance, 6-self-unacceptance, 7-acceptance of others, 8-unacceptance of others, 9-emotional comfort, 10-emotional discomfort, 11-internal control, 12-external control, 13-domination, 14-leading, 15-an escapism; b) A-setting the social desirability of responses, B-the tendency to overcome the rules and regulations, C-the tendency to addictive behaviour, D-a tendency to self-damaging and self-destroying behaviour, E-the tendency to aggression and violence, F-strong-willed control of emotional reactions, G-the tendency to delinquent behavior; C) continuous lines-direct connections, dashed lines-feedback, bold lines-correlation is significant at the level of $p \leq 0.01$, thin lines-correlation is significant at the level of $p \leq 0.05$.

At students-girls acceptance of others has the greatest impact on decreasing the tendency to different types of deviant behavior. High level of adaptation and self-acceptance negatively affects at the formation of the tendency to delinquent behavior, and strong-willed control of the emotional reactions increases with high emotional comfort and internal control.

As for the negative elements of social and psychological adaptation, the students-girls disadaptation leads to strengthening of the tendency to self-damaging and self-destroying behavior, as well as to aggression and violence. Self-unacceptance affects at strengthening the tendency practically to all forms of deviant behavior, except the tendency to addictive behavior. Unacceptance of others provokes the tendency to self-damaging 
and self-destroying behavior, the leading weakens of strong-willed control over manifestation of emotions. The students-girls' tendency to self-damaging and self-destroying, and also to delinventny behavior is strengthen with emotional discomfort and external control.

\section{Conclusion}

Students' positive elements of the social and psychological adaptation, such as high adaptation, self-acceptance and acceptance of others, internal control negatively impact on the possibility of addiction to different types of deviant behavior. As for negative elements of the same social and psychological adaptation, such as disadaptation, self-unacceptance and unacceptance of others, emotional discomfort, external control and escapism may lead to strengthen the tendency to deviant behavior.

The influence of positive and negative elements of social and psychological adaptation of students-boys on the tendency to deviant behavior is much lower than that of students-girls, as they use less significant correlation between the elements of social and psychological adaptation and forms of deviant behavior. They have only a high adaptation, self-acceptance and internal controls lead to reduce the risk of addiction to overcome rules and regulations and increase strong-willed control over emotions. Other positive aspects of social and psychological adaptation have no essential influence on the tendency to various forms of deviant behavior.

The risk of addiction to overcome the rules and regulations, to self-damaging and self-destroying behavior and aggression and violence, as well as delinquent behavior of students-boys increases with self-unacceptance, disadaptation and emotional discomfort and high unaceptance of others.

It is established the key element of social and psychological adaptation of students-girls is the acceptance of others, that reduce the tendency to most forms of deviant behavior.

As for the negative elements of social and psychological adaptation, the self-unacceptance of students-girls is the core element of social-psychological adaptation affecting the strengthening of the tendency to almost all forms of deviant behavior, except the tendency to addictive behavior. Other negative elements of social and psychological adaptation influence only on the tendency to some forms of deviant behavior.

\section{Recommendations}

The revealed features of interrelation of elements of social and psychological adaptation and forms of the tendency to deviant behavior have to be considered when developing the psychology and pedagogical programs directed on level reduction of tendency to deviant behavior of students. To minimize the risk of students tendency to deviant behavior, it is important to strengthen the positive elements of social and psychological adaptation, when working with students-boys it is necessary to focus on forming the skills of self-acceptance, and acceptance of others, manage their emotions, but working with students-girls it is important to strengthen their self-acceptance and acceptance of others.

\section{References}

Bessmertnaya, Y. A. (2014). Studying of tendency of studying senior classes to deviant behavior. Messenger of scientific organization of students, graduate students and young scientists, 1, 37-40.

Cheverikina, E. A. (2012). Social and psychological features of students of the higher education institutions inclined to dependence on psychoactive agents. Kazan pedagogical journal, 5-6, 126-132.

Cheverikina, E. A., Rakhimgarayeva, R. M., Sadovaya, V. V., Zakirova, V. G., Starodubets, O. D., \& Klemes, V. S. (2014). Socio-Psycological Characteristics of College Students Who are Prone to Addictions. Life Science Journal, 11(7s), 375-380.

Fetiskin, N. P., Kozlov, V. V., \& Manuylov, G. M. (2002). Socio-psychological diagnostics of development of the personality and small groups. Moscow.

Gadelshina, T. G. (2011). Structural and-level concept of psychological adaptation. Messenger of Tomsk state pedagogical university, 6(108), 161-164.

Gilemkhanova, E. N. (2013). Interrelation of adaptation with not constructive forms of social interaction at students inclined to addiction. Kazan pedagogical journal, 1, 54-58.

Heshmatollah, F. P., Ahmadi, A., \& Mahtabi, M. (2014). Review the role of divorce the children of delinquency. Academ Arena, 6(2), 62-65.

Kaletinskaya, M. I., \& Onufriyeva, V. V. (2014). Vzaimosvyaz of character aktsentuation with deviant behavior of teenagers. Psychology and pedagogic: Technique and problems of practical application, 37, $11-16$. 
Kleyberg, Y. A. (2004). Social psychology of deviant behavior (pp. 141-145). Moscow.

Masalimova, A. R., Zakirova, V. G., Chernova, Y. A., Drovnikov, A. S., Shaidullina, A. R., \& Sakhieva, R. G. (2014). Structure and Content of Mentors Psychological and Pedagogical Training Curriculum. Life Science Journal, 11(7s), 381-386.

Novick, N. N. (2014). Development of communicative activity in teenagers with deviant behavior. Education and self-development, 1(39), 212-217.

Radetskaya, K. V. (2013). Formation of a disciplinary responsibility at teenagers with deviant behavior. Problems of modern science and education, 4(18), 66-69.

Shahsavari, M. (2012). An Overview the relationship between anxiety and depression and the emergence of social deviance among students. Journal of American Science, 8(11), 322-324.

Yasnsaya, V. A. (2013). Identity distortions at teenagers with deviant behavior. Psychology and right, 14, 121-123.

Zhdanov, N. E. (2012). Risk as the prerequisite to deviant behavior of teenagers. Academic journal of Western Siberia, 2, 7-8.

Zmanovskaya, E. V., \& Rybnikov, V. Y. (2011). Deviant behavior of the personality and group (p. 352). St. Petersburg: St. Petersburg Press.

\section{Copyrights}

Copyright for this article is retained by the author(s), with first publication rights granted to the journal.

This is an open-access article distributed under the terms and conditions of the Creative Commons Attribution license (http://creativecommons.org/licenses/by/3.0/). 